\title{
Feasibility study of fusion bonding for carbon fabric reinforced polyphenylene sulphide by hot-tool welding
}

\author{
I. De Baere, W. Van Paepegem and J. Degrieck \\ Ghent University,Department of Materials Science and Engineering \\ Sint-Pietersnieuwstraat 41, B-9000 Gent, Belgium \\ Ives.DeBaere@UGent.be
}

\begin{abstract}
In recent years, there is a growing interest in joining techniques for thermoplastic composites as an alternative to adhesive bonding. In this manuscript, a fusion bonding process called hot-tool welding is investigated for this purpose and the used material is a carbon fabric reinforced polyphenylene sulphide. The welds are first observed through a microscope, after which the quality is experimentally assessed using a short three-point bending setup. A comparison is made between the welded specimens and the equivalent hot pressed specimens.

It can be concluded that the hot-tool welding process is very promising for the welding of material under study and that the short three-point bending setup proves interesting for evaluating bonds between composite specimens.
\end{abstract}

Keywords: Hot-Tool welding, Fusion Bonding, polyphenylene sulphide, Carbon, short beam strength

\section{Introduction}

An ideal structure would be designed without joints, since joints are potential sources of weakness and additional weight. In practice, however, the maximum size of a component is generally limited by the manufacturing processes. Moreover, demands such as inspection, accessibility, repair and of course transportation and assembly result in the fact that load-bearing joints cannot be avoided. This fact does not change when designing with fibre-reinforced composites; joints can be drastically reduced, but they will always be a part of a structure [1]. Well-established joining techniques for metallic structures are not directly applicable to composites. Typical problems when using mechanical fasteners include, among others: (i) stress concentrations created by the presence of holes and cut-outs; (ii) delaminations originating from the localised wear occurring during drilling; (iii) different thermal expansion of fasteners relative to the composite; (iv) creep of the composite when using bolted joints; (v) extensive time and labour requirements of hole drilling [2]. Adhesive bonding is inherently preferable to mechanical fastening because of the continuous connection, avoiding large stress concentrations induced by each discrete fastener hole. However, extensive surface preparation and long curing times make adhesive bonding labour intensive [3, 4]. Moreover, the need for recyclability [5] incites more and more manufacturers to choose materials and bonding systems which allow for recycling, excluding most thermosetting composites and adhesives [6].

Therefore, in recent years, the interest is growing in welding processes for thermoplastic composites, since (i) thermoplastics are difficult to bond because of their chemical inertness and (ii) the welding processes can reduce overall manufacturing cost and are expected to replace traditional assembly methods, such as adhesive and solvent bonding, mechanical fastening and co-consolidation bonding [7]. The fusion bonding of pure thermoplastics is already a well known and commonly applied production process, but the process parameters cannot be extrapolated to the welding of fibre-reinforced thermoplastics, since the reinforcement has a 
large influence: the material is no longer isotropic, heat conduction is influenced ... In general, these fusion bonding techniques can be categorised in three groups [7]: (i) frictional welding, including ultrasonic welding $[8,9,10,11]$; (ii) electromagnetic welding, including resistance welding [12, 13, 14, 17, 16, 15, 18, 19, 20, 21] and induction welding [22, 23] and (iii) thermal welding, including infrared welding [24] and hot-tool welding.

To determine the quality of the weld, quasi-static experiments till failure are considered. In general, there are various test setups available for examining the strength of adhesive bonds or the growth of delaminations [25, 26], such as (a) pure Mode I crack-growth with the double cantilever beam (DCB), (b) pure Mode II crack-growth with the end notch flexure beam (ENF), (c) combined Mode I and II with the Mixed Mode Bending (MMB) and (d) a structural test with the lap shear strength test (LSS). For evaluating the strength and the quality of the welds, the most commonly chosen experimental setups are the LSS [10, 14, 17, 16, 15] and DCB [14, 15, 24]. These methods give relevant information about the quality of the weld and are also quite useful for comparative studies [12]. With respect to the (finite element) modelling, a lot of attention is given on the modelling of the fusion bonding process itself [2], meaning that heattransfer, consolidation and crystallisation of the thermoplastic are considered $[11,19,20,21$, 27].

In this manuscript, the hot-tool welding process is considered as fusion bonding technique for a carbon fibre reinforced PolyPhenylene Sulphide. This technique has some interesting advantages, for instance: dissimilar thermoplastics can be welded, the temperature of the molten interfaces can be accurately controlled, surface inaccuracies can be taken into account during the process and it can handle complex geometries [7]. Furthermore, it is a relatively cheap process, since it does not require expensive machinery, as is the case for friction- and ultrasonic welding [2,7]. A disadvantage is that the thermoplastic polymer often tends to stick to the hottool, so special attention is paid to this aspect.

To evaluate the quality of the weld, a short-beam bending test, as described in the ASTM D2344/D 2344M 'Standard Test Method for Short-Beam Strength of Polymer Matrix Composite Materials and Their Laminates' is considered. This test has the advantage that it requires a lot less material than for the lap shear or mode I DCB test and it is a very simple test; force and displacement already give plenty of information.

In the next paragraph, the used materials and methods are discussed. This is followed by an overview of the experiments, after which the finite element modelling of the bending setup is given. Finally, some conclusions are drawn.

\section{Materials and Methods}

\subsection{Composite Material}

The material under study was a carbon fibre-reinforced polyphenylene sulphide (PPS), called CETEX. This material is supplied to us by Ten Cate. The fibre type is the carbon fibre T300J $3 \mathrm{~K}$ and the weaving pattern is a 5-harness satin weave with a mass per surface unit of $286 \mathrm{~g} / \mathrm{m}^{2}$. The 5-harness satin weave is a fabric with high strength in both directions and excellent bending properties.

The carbon PPS plates were hot pressed, and two stacking sequences were considered for this study: (i) $\left[\left(0^{\circ}, 90^{\circ}\right)\right]_{4 s}$, which was used to produce the welded joints and (ii) $\left[\left(0^{\circ}, 90^{\circ}\right)_{4},\left(90^{\circ}, 0^{\circ}\right)_{4}\right]_{\mathrm{s}}$ which is used as a benchmark to assess the quality of the welds. In both cases, $\left(0^{\circ}, 90^{\circ}\right)$ represents one layer of fabric, so the first sequence consists of eight layers, whereas the second consists of 16 layers.

The in-plane elastic properties of the individual carbon PPS lamina, determined by the dynamic modulus identification method as described in [28] and the tensile strength properties are listed in Table 1. 
The test coupons were sawn with a water-cooled diamond saw; the dimensions of the specimens are shown in Figure 1. The dimensions of the welded specimen are chosen so that from each weld, three bending coupons can be cut.
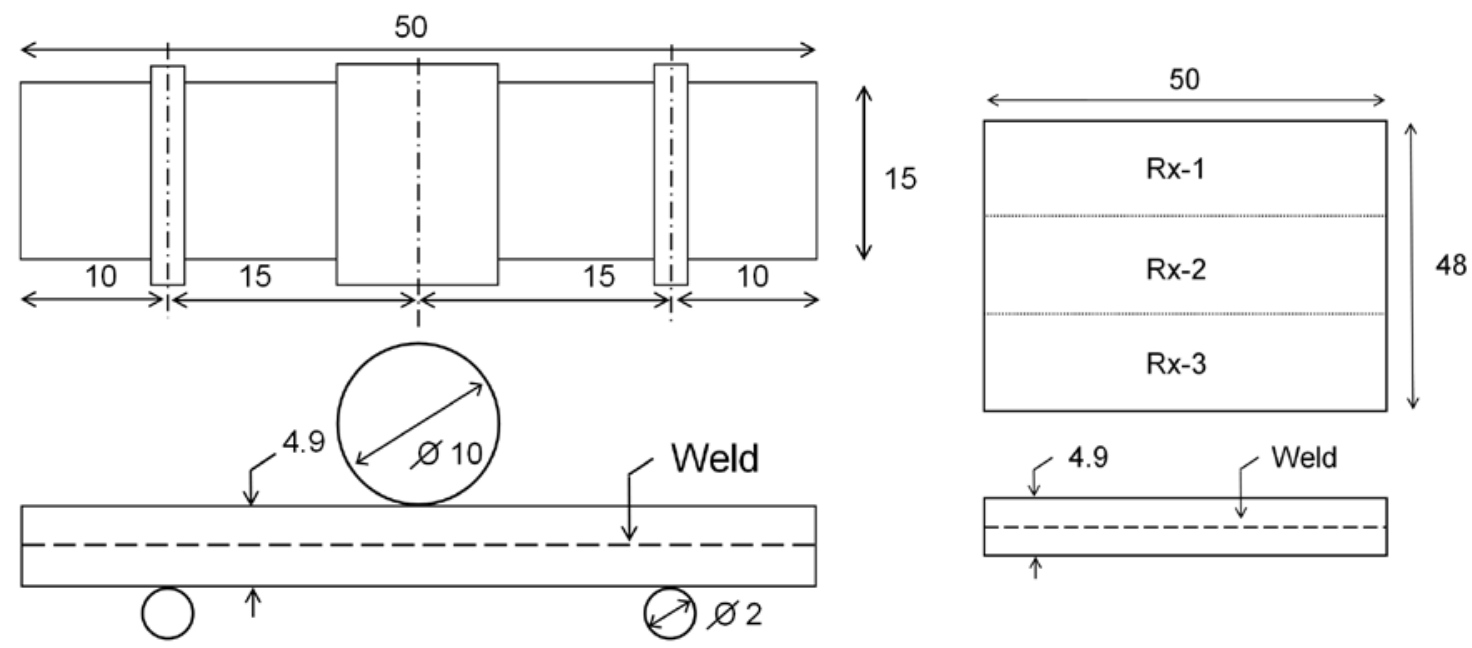

(a) Bending specimen

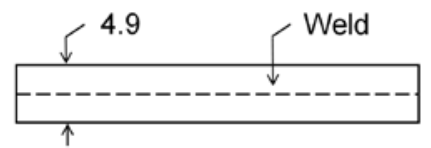

(b) Welded specimen Rx

Figure 1 Dimensions of the used specimens in millimetres.

To evaluate the strength, the short beam strength, as mentioned in the ASTM D2344/D 2344M 'Standard Test Method for Short-Beam Strength of Polymer Matrix Composite Materials and Their Laminates' is calculated using Equation 1:

$$
\tau^{s b s}=0.75 \frac{P_{m}}{b h} \quad[\mathrm{MPa}]
$$

With $\tau^{\text {sbs }}$ the short-beam strength [MPa]

$\mathrm{P}_{\mathrm{m}}$ the maximum load observed during the test $[\mathrm{N}]$

$\mathrm{b}$ the width of the specimen [mm]

$\mathrm{h}$ the height of the specimen [mm]

\subsection{Equipment}

The welding process was performed on a servo-hydraulic INSTRON 8801 tensile testing machine with a FastTrack 8800 digital controller and a load cell of $\pm 5 \mathrm{kN}$.

All bending tests were performed on an electromechanical INSTRON 5800R tensile testing machine with a FastTrack 8800 digital controller and a load cell of $\pm 10 \mathrm{kN}$. The quasi-static bending tests were displacement-controlled with a speed of $2 \mathrm{~mm} / \mathrm{min}$.

For the registration of the data, a combination of a National Instruments NI-USB-6251 data acquisition card and the SCB-68 pin shielded connecter were used. The load and displacement, given by the FastTrack controller, as well as the temperature from the thermocouple were sampled on the same time basis. 


\section{Experiments and discussion}

\subsection{Welding Process}

The fusion bonding process of choice is the 'hot-tool welding', of which the principle is illustrated in Figure 2 (a). The two surfaces to be welded are pushed against a heating element (step 1) and once the temperature is high enough, the two parts are pressed against one another with sufficient force (step 2). If necessary, extra filling material (thermoplastic sheets, reinforcement...) can be added to the weld, but this was not considered for this research. The 'hot-tool' is shown in Figure 2 (b). The surfaces of the parts to be welded make contact with the top and bottom contact plate respectively and the heat is generated using a heating resistor. A thermocouple is embedded near the surface of the hot-tool to control the temperature of the unit. The power of the resistor is controlled with the separate control unit, which takes the temperature into account. With this device, an area of $100 \mathrm{~mm}$ x $100 \mathrm{~mm}$ can be heated. For this research, an extra plate was added on top of the welding device, so that a contact area of $50 \mathrm{~mm}$ wide can be heated, in order to produce the specimens illustrated in Figure 1 (b). One of the disadvantages of hot-tool welding is that some thermoplastic material remains on the hot-tool. By using this plate, it is easier to keep the hot-tool clean and a number of films can be wrapped around this plate to avoid the sticking. Both TEFLON and KAPTON were assessed for this purpose, since these materials survive at the melting temperature of PPS, which is $280{ }^{\circ} \mathrm{C}$, but eventually, the best method was using no film at all and making contact between the steel plate and the composite. PPS always stuck to the film, but the film itself made the removing of the hot-tool prior to the consolidation phase a lot more cumbersome.

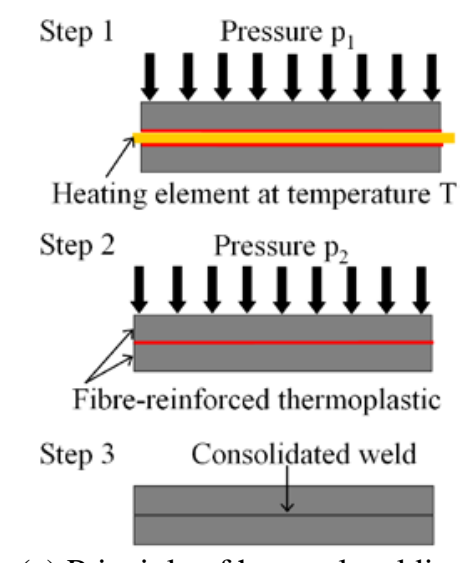

(a) Principle of hot-tool welding

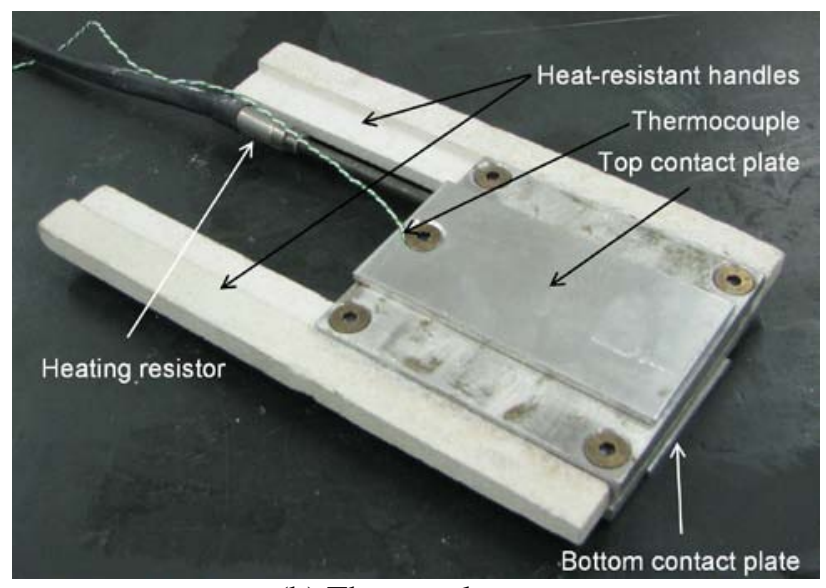

(b) The actual setup

Figure 2 The 'hot-tool' welding process and setup.

The actual setup is illustrated in Figure 3 (a). The two specimens are attached with double-sided tape to the top and bottom metal stamp to prevent the specimens from sticking to the hot-tool upon removal. For this picture, the lower specimen is taken long enough for visibility.

It was also assessed whether the PPS could be melted without being in contact with the hot-tool, by positioning the hot-tool less than $1 \mathrm{~mm}$ above the surfaces of the two parts (see Figure 3 (b)). As such, the PPS would never stick to the hot-tool. However, the heat generated by the hot-tool proved insufficient for melting the PPS, even after ten minutes of exposure. Possibly, due to the very good heat conduction of the carbon fibres and the metal stamps, the surface temperature could not exceed the melting temperature of the matrix. 


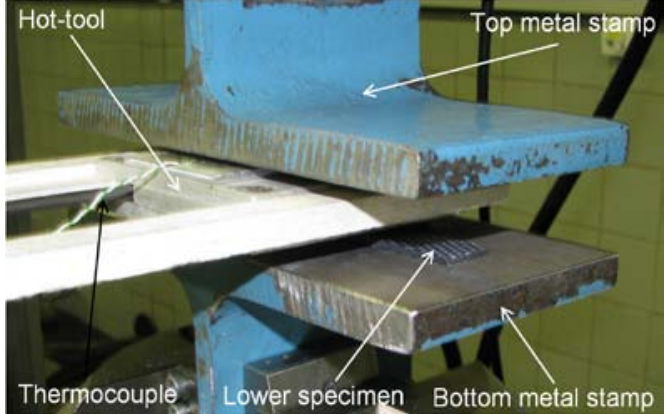

(a) Contact-heating the specimens

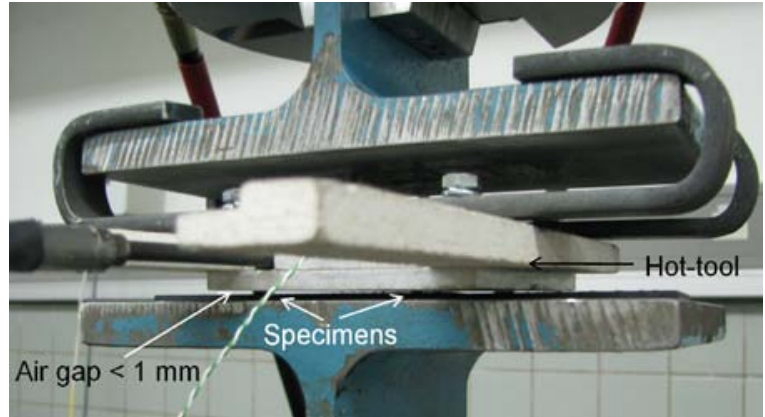

(b) Contactless-heating the specimens

Figure 3 Illustration of the heating step.

Once the optimal contact-pressure range has been determined, a standalone welding apparatus will be developed, but for this exploring research, a servo-hydraulic INSTRON 8801 tensile machine was used with a $5 \mathrm{kN}$ load cell to apply the pressure during welding and consolidation. During the welding phase, one can choose to hold the contact pressure constant or to press down until the weld has a certain thickness. For this study, the contact pressure was increased to the desired value and then the displacement was kept constant. Figure 4 illustrates the evolution of the contact pressure and the temperature during welding. The specimen was heated for about 80 seconds at an average temperature of $305^{\circ} \mathrm{C}$. The temperature was set at $310^{\circ} \mathrm{C}$ but because of the high thermal conductivity of carbon, a lot of heat was dissipated to the surroundings and to the tensile machine. Since the temperature of the hot-tool is monitored, only the evolution of the temperature during the heating phase is relevant.

There is some scatter on the contact pressure, since it is quite difficult to maintain a constant load, even in load-controlled mode. The decrease in contact pressure during consolidation is due to the fact that the pressure pushes the liquid PPS out of the weld. The specimen is removed once the weld is fully solidified. As can be seen, the change-over time, meaning the time between the end of heating and the start of the part mating, is about 7 seconds.

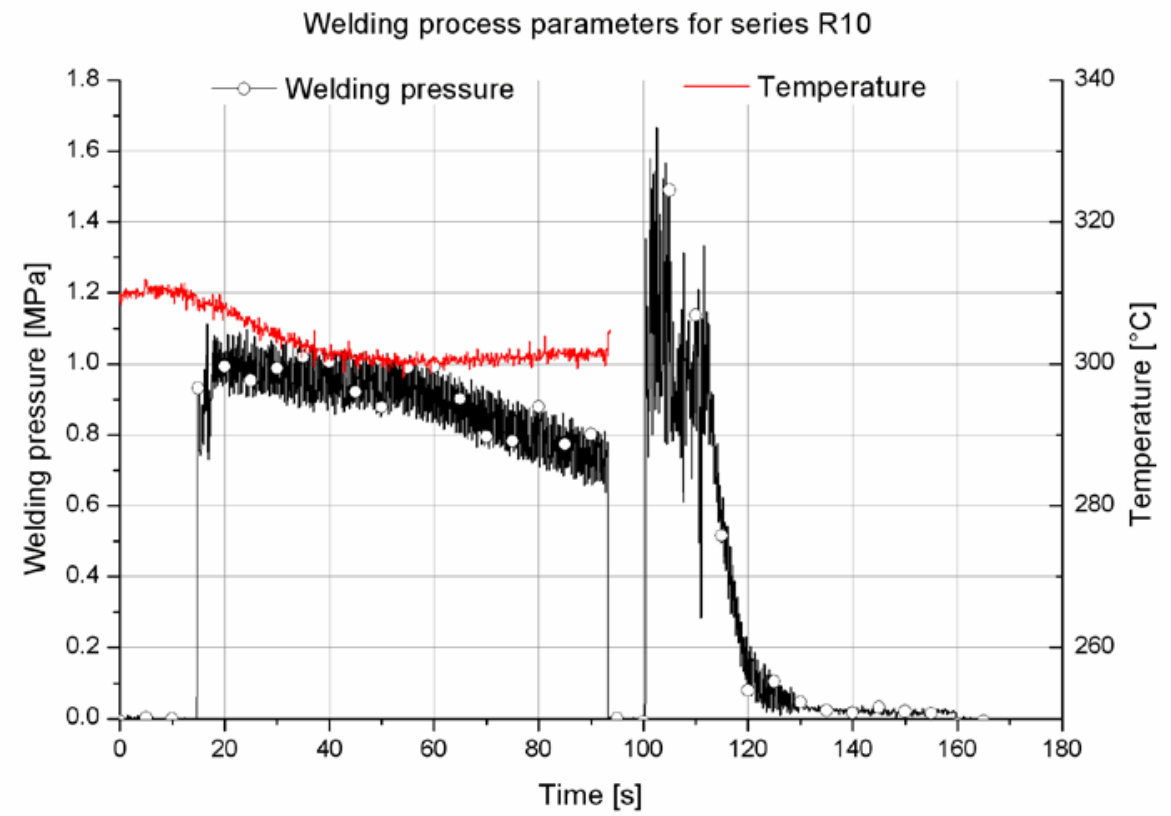

Figure 4 Illustration of the temperature and the welding pressure during the welding process 


\subsection{Non-Destructive Evaluation}

In order to investigate the quality of the weld, some of the bending specimens were polished and investigated under the microscope. Also, after failure, some microscopic pictures were taken to see where and how the fracture occurred.

Figure 5 shows an image of a not so successful weld. In this picture, an area can be seen were there is no PPS between the top and bottom specimen. Possible reasons may be that there was insufficient heating at that location; that the matrix stuck to the hot-tool rather than to the fibres or that insufficient pressure was applied.

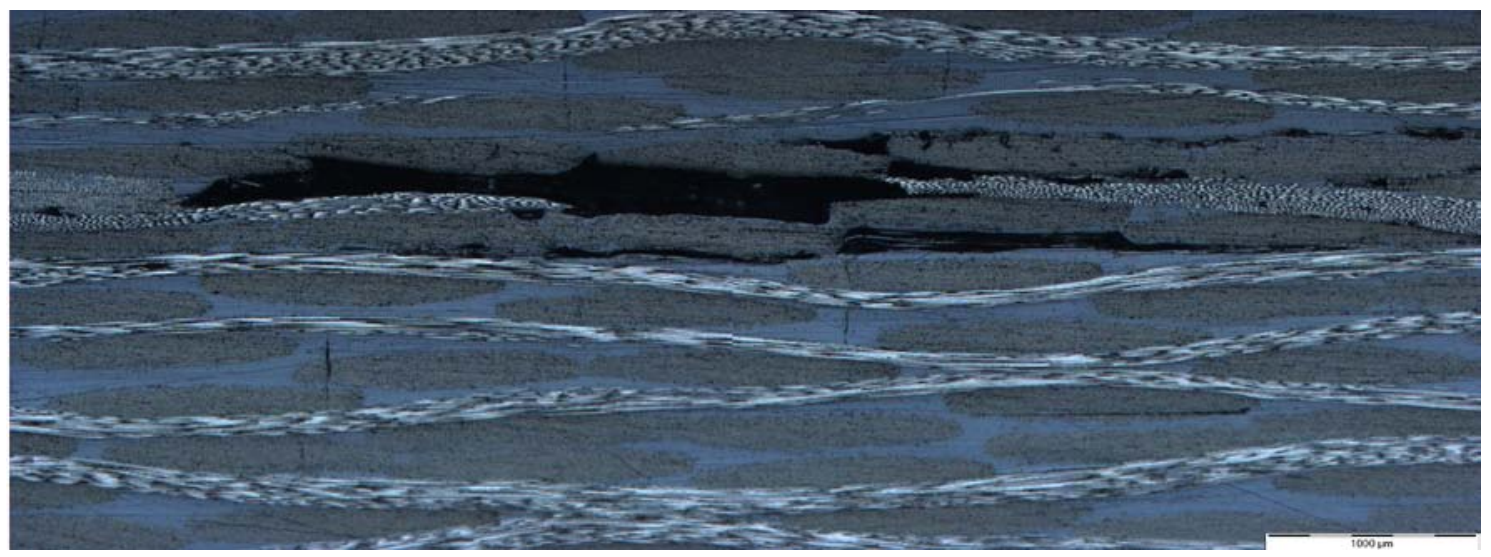

Figure 5 Microscopic image of a bad weld. An area with no PPS is clearly visible.

Figure 6 on the other hand shows the entire cross section of a bending specimen with a successful weld. The 16 different layers can clearly be distinguished and the weld lies in the middle, between the $8^{\text {th }}$ and $9^{\text {th }}$ layer. At that location, two horizontal fibre bundles make contact, with only very limited PPS in between. However, this does not necessarily mean it will be an inferior bond. First of all, this contact will only occur on limited places, given the nature of the 5-harness weave; second, between the warp and weft yarns, also limited PPS is present and third, mechanical anchoring of fibre-bundles may even increase the strength of the bond. 


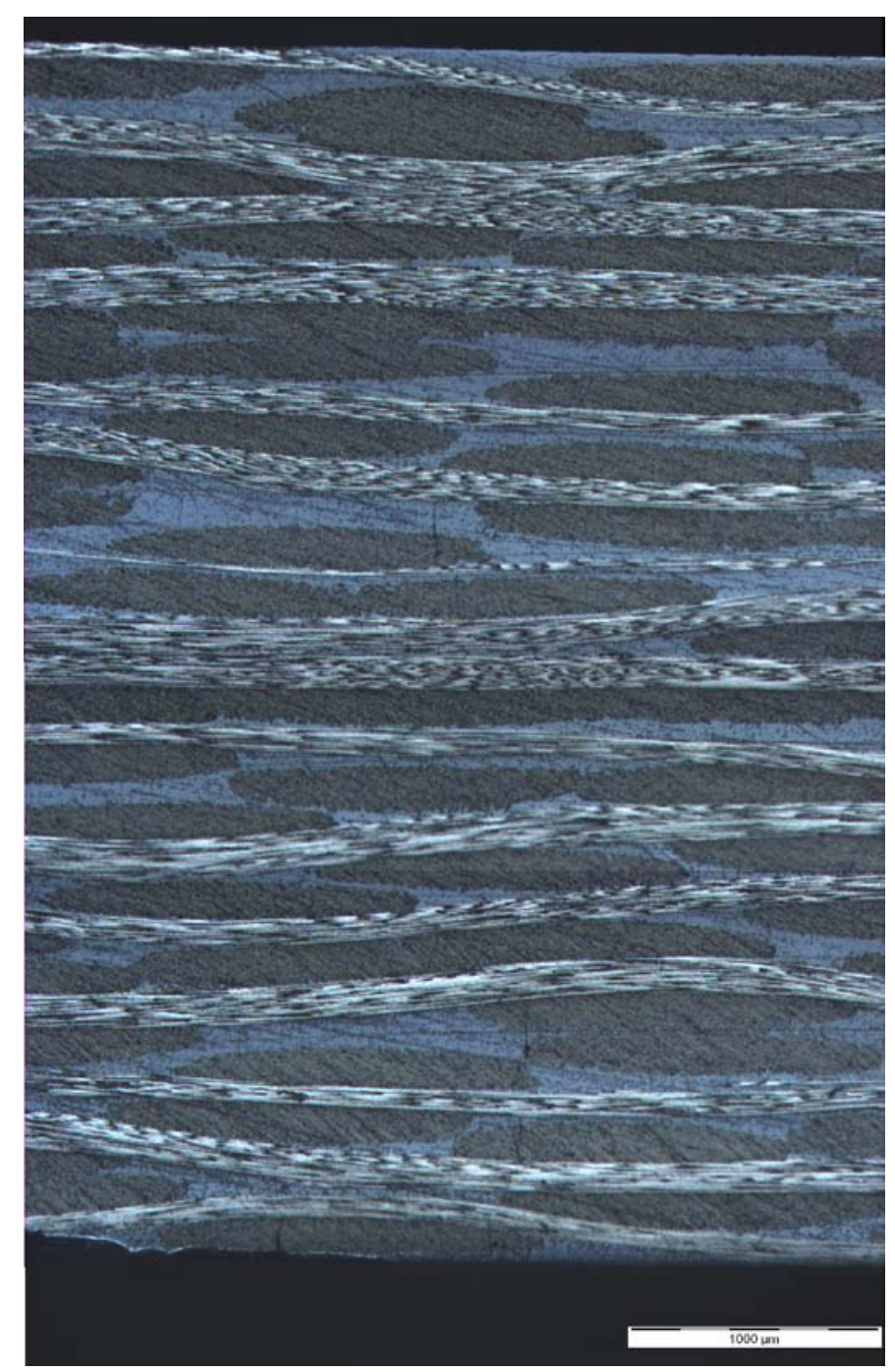

Figure 6 Microscopic image of a successful weld (specimen R14-1).

\subsection{Short Beam Strength Experiments}

In order to have some sort of reference value for the quality of the weld, two options were chosen. First, some specimens were adhesively bonded with adhesives that gave good results in the past [29]; depending on the bonded materials, these adhesives should give an ultimate shear strength between 10 and $15 \mathrm{MPa}$. However, the most relevant would be to compare the behaviour of the weld to the actual interlaminar behaviour of the composite. As such, an extra plate of sixteen layers was produced using the same production parameters as for the $\left[\left(0^{\circ}, 90^{\circ}\right)\right]_{4 \mathrm{~s}}$ plate, which was used for the to be welded parts. In order to have the same stacking sequence as for the welded specimen, the sequence $\left[\left(0^{\circ}, 90^{\circ}\right)_{4},\left(90^{\circ}, 0^{\circ}\right)_{4}\right]_{\mathrm{s}}$ was chosen rather than $\left[\left(0^{\circ}, 90^{\circ}\right)\right]_{8 s}$.

The results are shown in Figure 7, together with two bending tests on not bonded specimens. These are added to evaluate the bending stiffness when the bond has failed completely. For the adhesively bonded specimens, it can be clearly seen that once a load level around 1800 to 2000 $\mathrm{N}$ is reached, corresponding to a short-beam strength of $20.4 \mathrm{MPa}$, a very brittle interlaminar failure occurs and the force-displacement curve then follows the same trend as the curve from the unbonded specimens.

For the $\left[\left(0^{\circ}, 90^{\circ}\right)_{4},\left(90^{\circ}, 0^{\circ}\right)_{4}\right]_{\mathrm{s}}$ stacking sequence, which will be referred to as 'benchmark', two reproducible types of behaviour were found; each of them is represented in Figure 7. Benchmark2 yielded the highest failure load and failed purely due to bending loads, whereas 
Benchmark1 first fails due to a delamination underneath the indenting roll, causing the significant drop in load which can be seen in Figure 7. Next, the specimen again carries load, but the bending stiffness is significantly reduced compared to the un-delaminated specimen, until it fails due to bending loads. With respect to the short beam strengths, for benchmark1 and 2, an averaged value of respectively 51.2 MPa end 60.2 MPa was determined.

The quality of the weld could also be assessed by the evolution of the tangent slope on the force displacement curves. Indeed, first of all, there is a significant difference in this parameter for bonded and unbonded specimens, meaning that when failure of the weld is not clearly visible on the specimen, it can be determined by the drop in slope from fully bonded to unbonded. Second, a weld of lesser quality, due to manufacturing parameters on one hand, or damage on the other hand, should be visible by the tangent slope. Indeed, as illustrated by Alfredson et al. [30, 31], changing the properties of the shear deformable layer (in this case, the weld) clearly has an influence on the compliance of the beam.

For the welded specimens, it is yet to be determined whether the bending stiffness will show a gradual decay or a sudden drop and whether its absolute value depends on the used welding parameters. The load-displacement of the failed bonded specimens lies a little higher than the unbonded specimen, but this is due to the fact that only half of the bond failed, between one outer support and the centre support.

Initial bending tests for comparison purposes

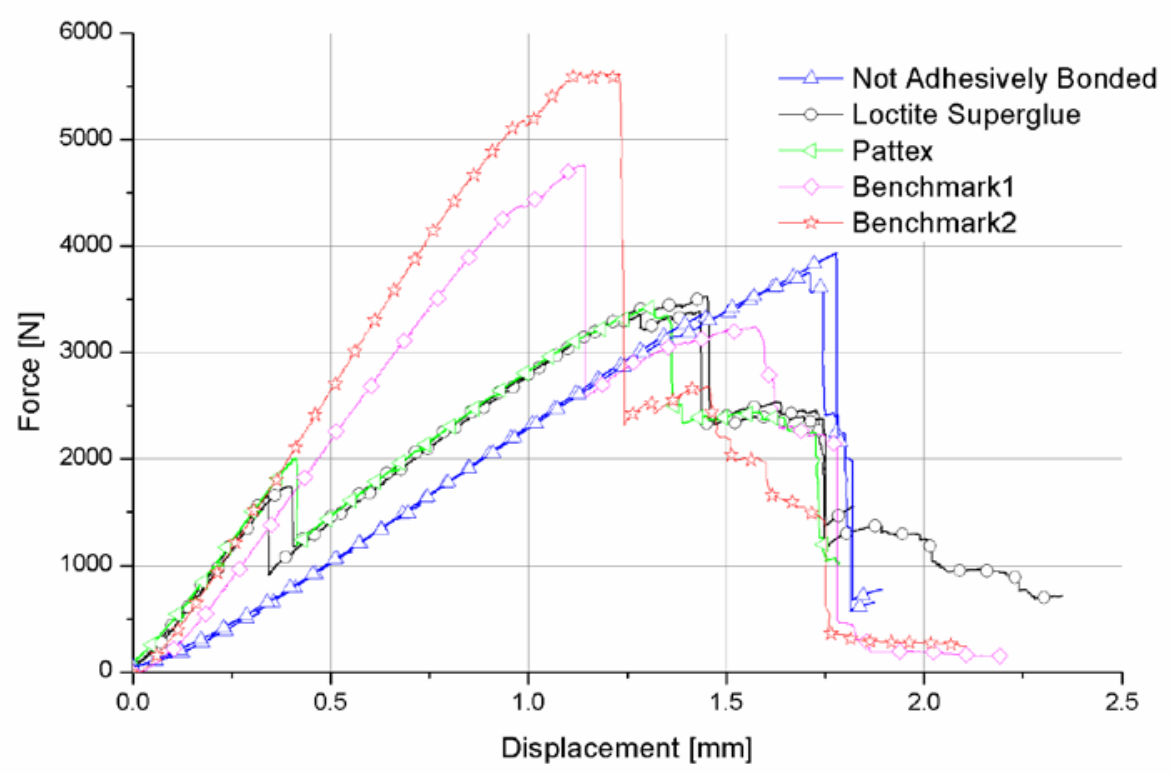

Figure 7 Bending experiments on adhesively bonded specimens and

A first series of tests were conducted to evaluate the reproducibility of the quality of the weld along the length of the weld. From each welded specimen, as illustrated in Figure 1 (b), three bending specimens are obtained. The results from one of those series, R10, are illustrated in Figure 8. As can be seen, the reproducibility is good, especially with respect to the bending stiffness. For this series, specimen R10-3 which was on the edge of the welding batch shows lower failure strength than the two other specimens. In general, it could be seen that specimen 3 showed a lower strength than the other two specimens. Closer examination of the welding setup showed that when welding pressure was applied, sometimes one of the stamps tilted a little, resulting in a lower pressure on that side of the specimen. This resulted in different consolidation parameters and consequently, different failure behaviour. Therefore, for other experimental results depicted in this manuscript, either specimen $\mathrm{Rx}-1$ or $\mathrm{Rx}-2$ from each series is illustrated as a representative for that welding process and the strength variation will be 
illustrated. It can also be noticed that the failure load is significantly higher than for the adhesively bonded specimens, illustrated in Figure 7, although it is lower than benchmark2.

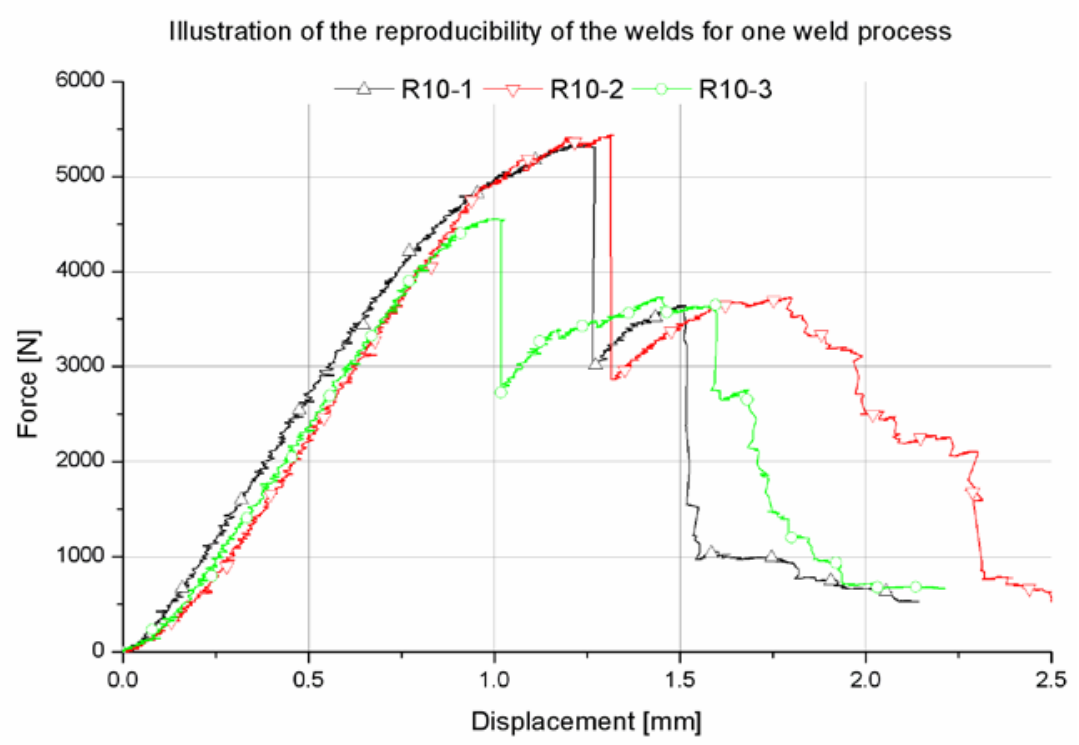

Figure 8 Bending tests on three specimens from one weld-process

Figure 9 shows several bending experiments on specimens from different welding processes. As can be seen, the reproducibility of the bending stiffness is high. It should be noted that the bending stiffness does not show a significant dependence on the welding parameters. With respect to the failure force, this value of course depends on the welding parameters, but even for a not so successful weld (R4-1) the failure force is still significantly higher than for the adhesively bonded specimens. It can also be noticed that most specimens tend to follow the curve of two separate, not bonded specimens after initial failure, meaning that failure is still quite brittle, although specimen R14-1 shows a very progressive failure. In general, the failure modes depend on the quality of the weld. The highest quality first showed very small delaminations in the mid plane and then failed due to bending loads (series R14). The mid quality welds first showed larger delaminations in the mid plane compared to the best quality, and then still failed due to a combination of bending loads and delaminations whereas the worst quality welds, similar to the adhesively bonded joints, failed purely due to delamination of the mid plane. These also failed quite brittle.

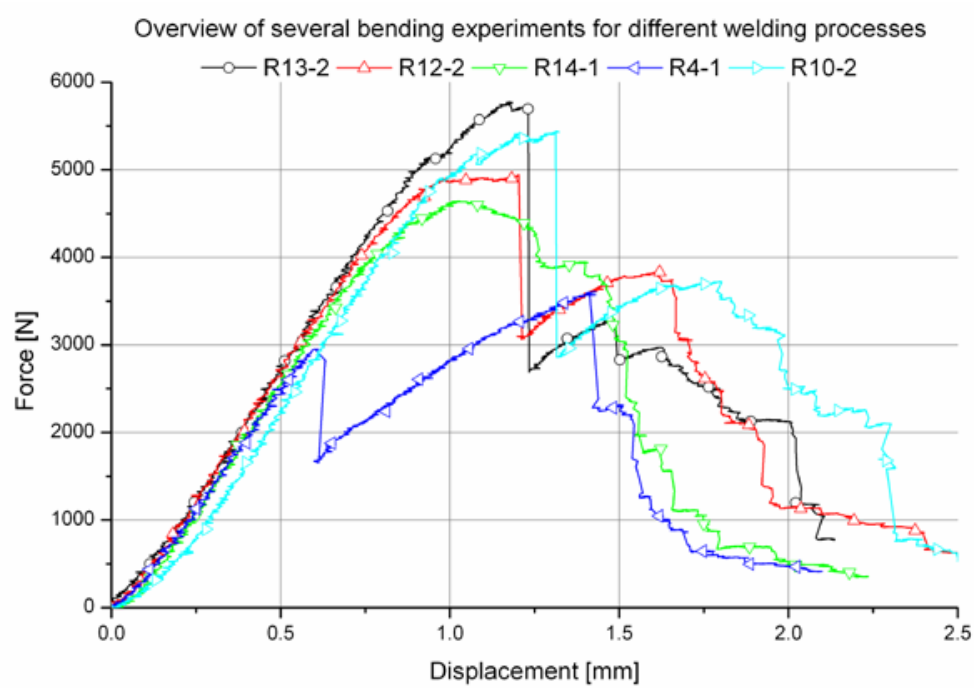

Figure 9 Force-displacement curves for specimens from different welding processes 
Table 2 shows an overview of the welding parameters for the experiments discussed in this paper. The contact pressure during consolidation was always the same as the contact pressure during the heating phase. This pressure was chosen close to $1 \mathrm{MPa}$, since this is also the consolidation pressure during the hot pressing of the composite plates. In earlier experiments, tests were done with contact pressures up to $3 \mathrm{MPa}$, but with results inferior to the ones shown here, because all liquid PPS was pushed out of the bond. Therefore, these experiments and settings are not discussed in this manuscript.

With respect to the temperature, the melting point of PPS is $280^{\circ} \mathrm{C}$, so temperatures lower were not considered. A temperature higher than $310^{\circ} \mathrm{C}$ was too high; on some locations of the welded surface, the PPS started to burn whereas on other locations (for the same weld) the PPS had not even melted. This is caused by the fact that the two separate specimens where not flat, but showed a little warping. Therefore, some area's of the plate mad contact with the hot-tool whereas others did not. Using higher contact pressures would solve this problem, but then all liquid PPS is pushed out of the weld, so no joint can be formed. This would also occur at lower temperatures, but then the process time was long enough for the carbon fibres to conduct and distribute the heat evenly, so that the entire surface melted. Joints realised at these higher temperatures were, of course, inferior. For the successful welds (R10, R12, R13 and R14), an average short-beam strength of $52.4 \mathrm{MPa}$ is achieved. The value of $\tau^{\text {sbs }}$ in Table 2 is the average value for the entire welding series.

Considering these values in comparison to the benchmarks, more specifically benchmark2 which failed under bending loads, rather benchmark1 which delaminated, it can be concluded that although the short beam strength is already quite high, the best weld has not yet been achieved. The main reason for this is that the combined effects of weld pressure, temperature and time on interdiffusion and optimal crystallisation have not yet been considered. This, however, can have a significant influence on the bond strength, has already been documented in literature, both under isothermal as non-isothermal conditions [32, 33, 34].

All current welds were manufactured within the boundary conditions of the currently used hot tool setup, where both the heating temperature and consolidation pressure can be controlled. However, a very important parameter for the crystallisation, namely the cooling rate during consolidation, cannot yet be controlled, since the two metal stamps currently used (Figure 3 (a)), are not equipped with a heating system. Of course, when designing the standalone welding setup, extra precautions such as temperature controlled moulds and an in situ temperature measurement, will be taken into account to achieve the optimal consolidation parameters for the PPS $[35,36]$ and other thermoplastics.

Finally, Figure 10 shows the occurring delaminations after failure, in the vicinity of the central failure under the central roll for the same specimen as was illustrated in Figure 6. As can be seen, two delaminations are present: the expected crack in the weld, but also a delaminations between the fourth and the fifth layer of the laminate, illustrating that the strength of the weld lies very near to the interlaminar shear strength of the laminate, since otherwise, only the central crack would be present. The latter was the case with the experiments where the two laminates were adhesively bonded. It can also be noticed that the central crack does not stay in the weld, but travels to the top layer of the bottom specimen. Furthermore, the crack does not travel between the two $0^{\circ}$ fibre bundles which make contact, illustrating the strength of the bond when mechanical anchoring of fibres is present. 


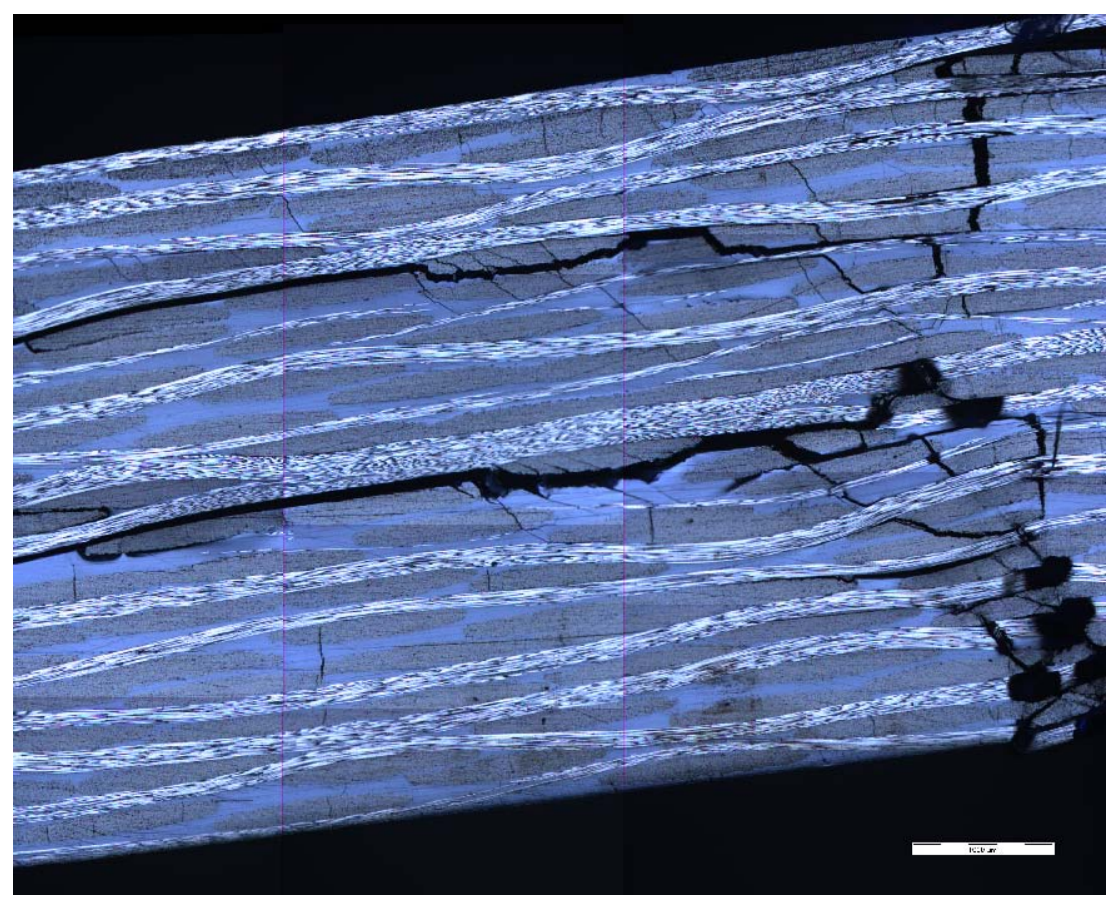

Figure 10 Illustration of the delaminations after failure (specimen R14-1).

\section{Conclusions}

The hot-tool welding process is suited for welding the carbon-fabric reinforced polyphenylene sulphide considered for this research. The interlaminar strength in a short three-point bending test is significantly higher than for adhesively bonded specimens and that the level of equivalent hot pressed plates is almost achieved. Furthermore, when observing the crack pattern of a welded specimen after bending failure, it was seen that not only the weld failed under interlaminar shear, but the composite laminate also showed delaminations. This means that the interlaminar strength of the weld is near to the interlaminar shear strength of the laminate.

For the welding parameters, a temperature between $295^{\circ} \mathrm{C}$ and $305^{\circ} \mathrm{C}$ in combination with a contact pressure of $1 \mathrm{MPa}$ for about 60 seconds shows best results. Other temperatures resulted in either no melting or burning of the PPS. Lower contact pressures resulted in bad consolidation and higher pressure pushed out all PPS, so no bond could be formed. The time interval is not so narrow, but in general it may be concluded that within the specified range of temperature and pressure, the quality of the weld is mostly dependent on the experience of the operator. For the successful welds, an average short-beam strength of 52.4 MPa was achieved.

\section{Acknowledgments}

The authors are highly indebted to the Fund of Scientific Research - Flanders (F.W.O.) for sponsoring this research and to Ten Cate Advanced Composites for supplying the material.

This research received no specific grant from any funding agency in the public, commercial, or not-for-profit sectors. 


\section{References}

[1] Hou M., Ye L. and Mai Y.W. An experimental study of resistance welding of carbon fibre fabric reinforced polyetherimide composite materl. APPLIED COMPOSITE MATERIALS (6) 35-49, 1999.

[2] Ageorges C, Ye L, Hou M , Advances in fusion bonding techniques for joining thermoplastic matrix composites: a review. COMPOSITES PART A-APPLIED SCIENCE AND MANUFACTURING 32 (6): 839-857 2001.

[3] Silverman E.M. and Griese R.A. Joining methods for graphite/peek thermoplastic composites. SAMPE JOURNAL 1989; 25(5):34-38

[4] Beevers, A. Welding: the way ahead for thermoplastics? ENGINEERING 1991;231:ACE11-2.

[5] Tietenberg T.H. Environmental economics and policy. $2^{\text {nd }}$ Edition. Addison-Wesley Education Pub. Inc. 1998.

[6] Loves W.E. Structural bonding for thermoplastics and composites. Adhes Age 1997. December 22-5

[7] Yousefpour A, Hojjati M, Immarigeon JP, Fusion bonding/welding of thermoplastic composites. JOURNAL OF THERMOPLASTIC COMPOSITE MATERIALS 17 (4): 303-341 JUL 2004.

[8] Gutnik VG, Gorbach NV, Dashkov AV, Some characteristics of ultrasonic welding of polymers. FIBRE CHEMISTRY 34 (6): 426-432 NOV-DEC 2002.

[9] Jandali G, Mallick PK, Vibration welding of continuous-fiber thermoplastic matrix composites. JOURNAL OF THERMOPLASTIC COMPOSITE MATERIALS 17 (4): 343-358 JUL 2004.

[10] Jandali G, Mallick PK. Vibration welding of a unidirectional continuous glass fiber reinforced polypropylene GMT. COMPOSITES PART A-APPLIED SCIENCE AND MANUFACTURING 36 (12): 1687-1693 2005.

[11] Suresh, K. S., Rani, A. Roopa, Prakasan, K., Rudramoorthy, R.. Modeling of temperature distribution in ultrasonic welding of thermoplastics for various joint designs. JOURNAL OF MATERIALS PROCESSING TECHNOLOGY 186 (1-3): 138-146 MAY 72007.

[12] Stavrov D, Bersee HEN. Resistance welding of thermoplastic composites - an overview. COMPOSITES PART A-APPLIED SCIENCE AND MANUFACTURING 36 (1): 39542005.

[13] Ageorges C, Ye L, Mai YW, Hou M. Characteristics of resistance welding of lap shear coupons. Part I: Heat transfer. COMPOSITES PART A-APPLIED SCIENCE AND MANUFACTURING 29 (8): 899-909 1998.

[14] Hou M, Yang MB, Beehag A, Mai YW, Ye L. Resistance welding of carbon fibre reinforced thermoplastic composite using alternative heating. COMPOSITE STRUCTURES 47 (1-4): 667-672 DEC 1999.

[15] Ageorges C, Ye L, Hou M. Experimental investigation of the resistance welding for thermoplastic-matrix composites. Part I: heating element and heat transfer. COMPOSITES SCIENCE AND TECHNOLOGY 60 (7): 1027-1039 2000.

[16] Hou M, Ye L, Mai YW. An experimental study of resistance welding of carbon fibre fabric reinforced polyetherimide (CF fabric PEI) composite material. APPLIED COMPOSITE MATERIALS 6 (1): 35-49 JAN 1999.

[17] Ageorges C, Ye L. Resistance welding of thermosetting composite/thermoplastic composite joints. COMPOSITES PART A-APPLIED SCIENCE AND MANUFACTURING 32 (11): 1603-1612 2001.

[18] Ageorges C, Ye L, Hou M. Experimental investigation of the resistance welding of thermoplastic-matrix composites. Part II: optimum processing window and mechanical performance. COMPOSITES SCIENCE AND TECHNOLOGY 60 (8): 1191-1202 2000. 
[19] Ageorges C, Ye L, Mai YW, Hou M. Characteristics of resistance welding of lap shear coupons. Part II. Consolidation. COMPOSITES PART A-APPLIED SCIENCE AND MANUFACTURING 29 (8): 911-919 1998.

[20] Colak ZS, Sonmez FO, Kalenderoglu V. Process Modeling and optimization of resistance welding for thermoplastic composites. JOURNAL OF COMPOSITE MATERIALS 36 (6): 721-744 2002.

[21] Ageorges C, Ye L. Simulation of impulse resistance welding for thermoplastic matrix composites. APPLIED COMPOSITE MATERIALS 8 (2): 133-147 MAR 2001.

[22] Kagan VA, Nichols RJ. Benefits of induction welding of reinforced thermoplastics in high performance applications. JOURNAL OF REINFORCED PLASTICS AND COMPOSITES 24 (13): 1345-1352 2005.

[23] W. Suwanwatana, S. Yarlagadda and J.W. Gillespie, Jr. Hysteresis heating based induction bonding of thermoplastic composites . COMPOSITES SCIENCE AND TECHNOLOGY 66 (11-12): 1713-1723 SEP 2006.

[24] Lamethe JF, Beauchene P, Leger L. Polymer dynamics applied to PEEK matrix composite welding. AEROSPACE SCIENCE AND TECHNOLOGY 9 (3): 233-240 APR 2005.

[25] Szekrenyes, Andras. Improved analysis of unidirectional composite delamination specimens. MECHANICS OF MATERIALS 39 (10): 953-974 OCT 2007.

[26] Mathews, Mary J. and Swanson, Stephen R. Characterization of the interlaminar fracture toughness of a laminated carbon/epoxy composite. COMPOSITES SCIENCE AND TECHNOLOGY 67 (7-8): 1489-1498 JUN 2007.

[27] Ageorges C, Ye L, Mai YW, Hou M. Characteristics of resistance welding of lap-shear coupons. Part III. Crystallinity. COMPOSITES PART A-APPLIED SCIENCE AND MANUFACTURING 29 (8): 921-932 1998.

[28] De Baere I., Van Paepegem W., Degrieck J., Sol H., Van Hemelrijck D. and Petreli A., Comparison of different identification techniques for measurement of quasi-zero Poisson's ratio of fabric reinforced laminates. Composites A 38 (9) pp. 2047-2054. (2007)

[29] De Baere I., Experimental and Numerical Study of Different Setups for Conducting and Monitoring Fatigue Experiments of Fibre-Reinforced Thermoplastics. doctoral-thesis, Ghent University, ISBN 987-90-8578-196-7, February 2008

[30] Alfredsson, K. S., T. A. Bogetti, L., A. Carlsson, J. W. Gillespie, Jr., A. Yiournas, "Flexure of Beams with an Interlayer - Symmetric Beams with Orthotropic Adherends," Journal of Mechanics of Materials and Structures, 3 (1), pp. 45-62, Jan. 2008.

[31] Alfredsson, K. S., J. W. Gillespie, Jr., L. A. Carlsson, T. A. Bogetti, and A. Yiournas, "Flexure Analysis of Unsymmetric Orthotropic Beams with an Interlayer," International Journal of Solids and Structures, 46 (10), pp. 2093-2110, May 2009.

[32] Bastien, L. J. and J. W. Gillespie Jr., "A Nonisothermal Healing Model for Strength and Toughness of Fusion Bonded Joints of Amorphous Thermoplastics," Polymer Engineering and Science, Vol. 31, No. 24, pp. 1720-1730, December 1991

[33] Tierney, J., J. W. Gillespie, Jr., "Modeling of In-Situ Strength Development for the Thermoplastic Composite Tow Placement Process,” Journal of Composite Materials, 40 (16) pp. 1487-1506, 2006.

[34] Tierney, J. and J. W. Gillespie, Jr. "Crystallization Kinetics Behavior of PEEK-based Composites Exposed to High Heating and Cooling Rates," Composites Part A: Applied Science and Manufacturing, Vol. 35, pp. 547-558, 2004.

[35] Ma CM, Hu JT, Liu WL, Hsai HC, SHieh BY, Lui RS. The thermal, rheological and morphological properties of poly phenylene sulphide and polyetheretherketone resins and composites. Part 1. Assessment of crystallinity. SAMPE Quaterly 16 (4) pp 22 - 30 (1985)

[36] Kenny JM and Maffezzoli A.Crystallization kinetics of poly(phenylene sulfide) (PPS) and PPS/Carbon Fiber composites. Polymer Engineering and Science 31 (8) pp 607-614 
(1991) 
Table 1 Elastic and strength properties of the CETEX ${ }^{\circledR}$ material

\begin{tabular}{ccccccccc}
\hline $\mathrm{E}_{11}$ & $\mathrm{E}_{22}$ & $v_{12}$ & $\mathrm{G}_{12}$ & $\mathrm{X}_{\mathrm{T}}$ & $\varepsilon_{11}^{\text {ult }}$ & $\mathrm{Y}_{\mathrm{T}}$ & $\varepsilon_{22}^{\text {ult }}$ & $\mathrm{S}_{\mathrm{T}}$ \\
{$[\mathrm{GPa}]$} & {$[\mathrm{GPa}]$} & {$[-]$} & {$[\mathrm{GPa}]$} & {$[\mathrm{MPa}]$} & {$[-]$} & {$[\mathrm{MPa}]$} & {$[-]$} & {$[\mathrm{MPa}]$} \\
56.0 & 57.0 & 0.033 & 4.175 & 736.0 & 0.011 & 754.0 & 0.013 & 110.0 \\
\hline
\end{tabular}


Table 2 Overview of the welding parameters for the experiments shown in this paper, together with the short-beam strength (Equation 1)

\begin{tabular}{ccccc}
\hline Process & Contact pressure $[\mathrm{MPa}]$ & Temperature $\left[{ }^{\circ} \mathrm{C}\right]$ & Heating time $[\mathrm{s}]$ & $\tau^{\mathrm{sbs}}[\mathrm{MPa}]$ \\
R4 & 0.9 & 290 & 60 & $30 \pm 5.2$ \\
R10 & 0.9 & 300 & 75 & $55.0 \pm 0.5$ \\
R12 & 1 & 310 & 20 & $46.9 \pm 3.5$ \\
R13 & 1 & 290 & 100 & $54.8 \pm 4.2$ \\
R14 & 1 & 300 & 70 & $52.7 \pm 5.3$ \\
\hline
\end{tabular}

